\title{
Aryl hydrocarbon receptor agonists trigger avoidance of novel food in rats
}

\author{
Selma Mahiout and Raimo Pohjanvirta
}

Department of Food Hygiene and Environmental Health, Faculty of Veterinary Medicine, University of Helsinki, Mustialankatu 1, FI-00790 Helsinki, Finland

Corresponding author:

Selma Mahiout

Dept. of Food Hygiene and Environmental Health

Faculty of Veterinary Medicine

Mustialankatu 1

FI-00790 Helsinki, Finland

Email: selma.mahiout@helsinki.fi

Phone: 00358-2941-57427

Fax: 00358-2941 57161 


\begin{abstract}
The aryl hydrocarbon receptor (AHR) is a ligand-activated transcription factor that mediates the toxicity of dioxins, but also plays important physiological roles, which are only beginning to unfold. Previous studies have surprisingly unveiled that low doses of the potent AHR agonist TCDD induce a strong and persistent avoidance of novel food items in rats. Here, we further examined the involvement of the AHR in the avoidance response in Sprague-Dawley rats with three established AHR agonists: 6-formylindolo(3,2b)carbazole (FICZ), $\beta$-naphthoflavone (BNF) and benzo[a]pyrene (BaP); with a novel selective AHR modulator (C2); and with an activator of another nuclear receptor, CAR: 2,4,6-tryphenyldioxane-1,3 (TPD). As sensitive indices of AHR or CAR activity, we used Cyp1a1 and Cyp2b1 gene expression, as they are, respectively, the drug-metabolizing enzymes specifically regulated by them. We further attempted to address the roles played by enhanced neophobia and conditioned taste aversion (CTA) in the avoidance behaviour. All AHR agonists triggered practically total avoidance of novel chocolate, but the durations varied. Likewise, acutely subtoxic doses of C2, differing by 25 -fold, all elicited a similar outcome. In contrast, TPD did not influence chocolate consumption at all. If rats were initially accustomed to chocolate for $6 \mathrm{~h}$ after single FICZ or BNF exposure, avoidance was still clearly present two weeks later when chocolate was offered again. Hence, the avoidance response appears to specifically involve the AHR instead of being triggered by induction of intestinal or hepatic nuclear receptor signalling in general. It is also shared by both endogenous and exogenous AHR activators. Moreover, this behavioural change in rats seems to contain elements of both CTA and enhanced neophobia, but further clarification of this is still required.
\end{abstract}

Keywords: AH receptor; Novel food avoidance; FICZ; Benzo[a]pyrene; $\beta$-Naphthoflavone; TPD 


\section{Introduction}

The aryl hydrocarbon receptor (AHR) is an evolutionarily ancient, evidently over 600 million-year-old protein. It is a ligand-activated transcription factor that is present in most cell types across all vertebrates, including humans [reviewed in (Hahn and Karchner 2011)]. Evidence is rapidly accumulating to show that the AHR is involved in numerous physiological phenomena, even if its role is currently often incompletely understood. The endogenous functions of the AHR elucidated so far include participation in the metabolism of xenobiotics, regulation of reproduction, development, cell growth and differentiation, and autoimmunity (Esser, et al. 2009, Fujii-Kuriyama and Kawajiri 2010, McMillan and Bradfield 2007). Recent studies have further revealed a major role for the AHR in the control of intestinal microbiota and innate immunity (Kiss, et al. 2011, Lee, et al. 2012, Moura-Alves, et al. 2014), rendering it thus a promising new target for pharmacological research in several fields.

The molecular mechanism of AHR action has been revealed in detail for transcriptional induction of a drugmetabolizing enzyme, CYP1A1, but it is believed to represent a more general pattern. In inactive state, the AHR is located in the cytosol in association with the chaperone proteins HSP90, XAP2 and p23. Binding of a ligand such as 2,3,7,8-tetrachlorodibenzo-p-dioxin (TCDD) triggers transformation in the protein structure causing the AHR to translocate into the nucleus. There it sheds the cytosolic protein partners and dimerizes with a structurally related protein, ARNT. The AHR-ARNT dimer then binds to the DNA at specific enhancer sites called dioxin response elements (DREs) in the promoter region of the Cyp1a1 gene, eventually leading to induced transcription of CYP1A1 mRNA (Ma 2011). This is an adaptive, chiefly beneficial physiological response that leads to augmented detoxification capacity. Induction of Cyp1a1 is also a rapid and highly sensitive marker for AHR activation (Abraham, et al. 1988).

While the AHR is notably promiscuous with an extensive array of both endogenous and exogenous ligands, no single endogenous substance has stood out as its primary physiological activator in all tissues to date. Therefore, the best-known and most studied role of the AHR so far is its indispensable involvement in the mechanism of toxicity of a large group of environmental contaminants encompassing halogenated and polycyclic aromatic hydrocarbons, of which dioxins are particularly important. Dioxins (polychlorinated dibenzo-p-dioxins, dibenzofurans and co-planar PCBs) are mostly by-products of industrial thermal processes and incomplete combustion (Shen, et al. 2009, White and Birnbaum 2009). They are chemically highly persistent and hydrophobic, which leads to their accumulation in the food chain, and eventually in humans (Kiviranta, et al. 2002). The most toxic dioxin is TCDD (Van Den Berg, et al. 1998). It causes a multitude of 
adverse effects in laboratory animals including hypophagia, wasting syndrome, developmental toxicity, endocrine disruption, carcinogenicity and immunotoxicity (Pohjanvirta and Tuomisto 1994). The current consensus is that these result from inappropriate and untimely activation of the AHR (Bock and Köhle 2006, Denison, et al. 2011).

In the course of the evolution, two related but distinct behavioural mechanisms have evolved to protect animals from eating potentially toxic novel food items: taste neophobia and conditioned taste or food aversion (CTA). Neophobia is considered an innate, protective behaviour that can be experienced towards food, but also novel objects or environments. It is a novelty-induced fear response, which typically subdues rapidly when novel food is deemed safe and becomes familiar. CTA, on the other hand, is a behavioural change seen in both humans and animals, where aversion to the taste or odour of a specific foodstuff (conditioned stimulus) develops due to nausea or gastrointestinal malaise (unconditioned stimulus) that is experienced in conjunction to or relatively soon after consuming the food, regardless of whether the two events are causally related [reviewed e.g. in (Lin, et al. 2014, Verendeev and Riley 2012, Welzl, et al. 2001)]. It is considered a special form of classical conditioning, where the trigger and effect can be even several hours apart. CTA has been interpreted as a mechanism serving to protect the animal from ingesting harmful chemicals and microbes. As such, it protects from foods that, based on a previous encounter, might be harmful, and may persist even for weeks or months (Lin, et al. 2014, Verendeev and Riley 2012). It can occur with familiar food, but is usually more pronounced and persistent with unfamiliar foodstuffs. Interestingly, studies in laboratory animals suggest that the feeling of nausea or gastrointestinal discomfort may not always be required for the effect to take place, and it can even be instigated when the animals are unconscious while exposed to CTA-inducing compounds [reviewed e.g. in (Grant 1987, Lin, et al. 2014, Verendeev and Riley 2012)]. Although CTA has, as a peculiar form of learning behaviour, been extensively studied for decades, its molecular basis has remained elusive [reviewed e.g. in (Bermudez-Rattoni 2014, Guzmán-Ramos and Bermúdez-Rattoni 2011, Núñez-Jaramillo, et al. 2010)]. As proposed by Lin et al. (2016), taste neophobia and CTA may be intertwined so that the former primes the CTA mechanism to become engaged when suspicions of toxicity are aroused, thereby enhancing CTA.

Based on an originally fortuitous and unexpected finding, it was previously shown that low doses of TCDD that do not cause overt acute toxicity, induce strong avoidance of novel food items in rats, and this phenomenon seemed to correlate with induction of Cyp1a1 drug-metabolizing enzyme in the liver (Lensu, et al. 2011a, Lensu, et al. 2011b, Tuomisto, et al. 2000). Unlike many other TCDD-induced effects, the avoidance emerges rapidly, within hours of a single TCDD exposure that is coupled with presentation of a previously 
unfamiliar food. This response has been shown to be induced by TCDD towards such novel foods as milk chocolate and cheese, as well as sucrose (10\%) and saccharin (0.25\%) solutions (Lensu, et al. 2011a, Tuomisto, et al. 2000). Even a change in the texture of the standard feed (pelleted vs. powdered) is sufficient to induce avoidance after TCDD exposure (Lensu, et al. 2011a). The avoidance is strikingly persistent: when chocolate was offered immediately after TCDD exposure, practically total avoidance of it evolved and persisted for 6 weeks, after which it started to gradually fade, although by the end of the observation period (76 days), the consumption was still below control level (Lensu, et al. 2011a). Interestingly, the well-documented rat strain differences in sensitivity to TCDD (Pohjanvirta, et al. 1993) are not reflected in susceptibility to the novel food avoidance induced by TCDD: all tested strains/lines exhibited comparable aversive behaviour (Lensu, et al. 2011b, Tuomisto, et al. 2000). For example, the $E_{50}$ values for TCDD-caused avoidance for three differently TCDD-responsive rat lines proved to be $0.36,1.07$ and $0.34 \mu \mathrm{g} / \mathrm{kg}$ (Lensu, et al. 2011b). The corresponding $L D_{50}$ values of TCDD for these rat lines (males) are $>10,000,830$, and $40 \mu \mathrm{g} / \mathrm{kg}$ (Tuomisto, et al. 1999). Total abstinence from chocolate in all three lines was seen at $3 \mu \mathrm{g} / \mathrm{kg}$. Hence, this induced avoidance is one of the most sensitive behavioural effects TCDD has been shown to exert in adult laboratory animals.

In the present study, we were interested in further examining the involvement of the AHR in the avoidance response, and to find out whether in addition to TCDD, also shorter-acting, less potent AHR agonists are able to induce it in rats. This cannot be taken for granted: the wasting syndrome is primarily due to hypophagia and thus represents another conspicuous alteration in feeding behaviour caused by TCDD; however, other types of AHR activators do not elicit it even at high and repeated doses (Neal, et al. 1979). In the case of the avoidance response, we hypothesized that transient AHR activation could suffice, and thus also other AHRactivators might be able to mount it. To test this, we used three well-established AHR agonists: the endogenously generated potent agonist, tryptophan metabolite FICZ (6-formylindolo(3,2-b)carbazole) (Mukai and Tischkau 2007, Wei, et al. 1998, Wincent, et al. 2009, Wincent, et al. 2012), $\beta$-naphthoflavone (BNF) (Hodek, et al. 2013, Sugihara, et al. 2008) and benzo[a]pyrene (BaP) (Hodek, et al. 2013, Kaisarevic, et al. 2015). We also tested a novel selective AHR modulator, C2 (N-acetyl-N-phenyl-4-acetoxy-5-chloro-1,2dihydro-1-methyl-2-oxo-quinoline-3-carboxamide), which represents an $\mathrm{N}$-hydrogen metabolite of the autoimmune disease drug compound laquinimod. The doses were selected so as to reliably bring about activation of hepatic AHR signalling as assessed by Cyp1a1 mRNA or protein expression, based on the studies cited above and (for the high dose of $\mathrm{C2}$ ) our own unpublished data.

While the available pharmacokinetic information for these compounds is insufficient to verify exact half-lives, they are all likely to be shorter-acting than TCDD based on the duration of their CYP1A1 induction potential 
seen in these studies. In addition, they also have either comparable or lower AHR binding affinities than TCDD. In vitro, FICZ binds to the AHR with even somewhat greater affinity than TCDD (Kd values of 0.07 and $0.48 \mathrm{nM}$, respectively) (Rannug, et al. 1987, Rannug, et al. 1995), but it is metabolized extensively and rapidly in vivo, foremost by CYP1A1 (Bergander, et al. 2003, Bergander, et al. 2004). The binding avidity of BaP to the AHR is 4-9 times weaker than that of TCDD but 1.4-fold as high as that of BNF (Okey, et al. 1984, Roy, et al. 1988). For C2, preliminary studies have suggested that its in vitro potency to induce Cyp1a1 is at least as high as that of TCDD (Mahiout et al., manuscript in preparation)

We also hypothesized that crucial to the avoidance response was specifically the induction of AHR instead of activation of one or more other nuclear receptors that would also result in induction of xenobiotic metabolizing enzymes. Therefore, the avoidance response should not be brought about by a phenobarbitallike metabolic enzyme inducer that activates the constitutive androstane receptor (CAR) instead of AHR: 2,4,6-tryphenyldioxane-1,3 (TPD) (Pustylnyak, et al. 2009). Induction of Cyp1a1 and Cyp2b1 were determined as sensitive indices of activation of AHR and CAR, respectively, as they are the drug-metabolizing enzymes specifically regulated by them. We also attempted to clarify the roles of enhanced neophobia and CTA in the avoidance of unfamiliar food behaviour. Chocolate was chosen as the novel food item, as it has been used in the previous studies with TCDD, rats normally find it highly palatable, its consumption is easy to measure, and it keeps well at room temperature. 


\section{Materials and methods}

\subsection{Chemicals}

FICZ was purchased from Enzo Life Sciences (Farmingdale, NY, USA) and BNF and BaP from Sigma-Aldrich (St. Louis, MO, USA). TPD was kindly provided by Dr. Vladimir O. PustyInyak (Institute of Molecular Biology and Biophysics SB RAMS, Novosibirsk, Russia). C2 was kindly provided by Dr. Lars Pettersson (Immunahr AB, Lund, Sweden). FICZ and TPD were first dissolved into DMSO (Sigma-Aldrich, St. Louis, MO, USA) and then diluted with sunflower oil (Keiju, Bunge Finland Oy, Raisio, Finland) to achieve solutions for animal treatment [final DMSO concentrations 2.5\% (v/v)]. BNF and BaP were mixed with DMSO and sunflower oil and then heated in a $+95^{\circ} \mathrm{C}$ water bath for $1 \mathrm{~h}$, resulting in suspensions [final DMSO concentrations $2.5 \%(\mathrm{v} / \mathrm{v})$ ]. C2 was mixed with PEG-400 (Sigma, St. Louis, MO; USA) and heated in a $+95^{\circ} \mathrm{C}$ water bath for $30-60 \mathrm{~min}$ to dissolve.

\subsection{Animals and their husbandry}

Sprague-Dawley rats (males, 7-8 weeks at dosing) were purchased from Harlan Netherlands. After arrival, they were housed in pairs and acclimatised to study conditions and handling for a minimum of one week. Throughout the studies, they were housed in individually ventilated cages (Green Line IVC Sealsafe PLUS Rat, Techniplast, West Chester, PA, USA), and maintained on a 12-h light/dark cycle with a red light in the room during the night (except for Exp. 1A). The lights came on at 6 a.m. The bottom of the cages was covered with aspen wood bedding (Tapvei, Harjumaa, Estonia), and each cage enriched with a transparent red plastic hiding tube, nesting material and chew blocks (both aspen wood, Tapvei, Harjumaa, Estonia). Commercial pelleted rat chow (Teklad Global 16\% Protein Rodent Diet, Teklad Diets, Madison WI, USA) and filtered, UVirradiated tap water were available ad libitum. The animal room was air-conditioned, the temperature kept at $22 \pm 1^{\circ} \mathrm{C}$ and relative humidity at $38-75 \%$ (typically $50 \%$ ).

All studies were authorized by the National Animal Experiment Board in Finland (Eläinkoelautakunta, ELLA; project licence code: ESAVI/6882/04.10.03/2012). All procedures were conducted in accordance with the Directive 2010/63/EU of the European Parliament and of the Council.

\subsection{Experimental design}

For the duration of the experiments (starting 1-6 days prior to exposure), the rats were caged singly to allow individual measurement of chocolate consumption. In the experiments, they were all dosed intragastrically 
by gavage ( $4 \mathrm{ml} / \mathrm{kg}$ unless specified otherwise) after a 3-h fast, for which chow was removed from the feed hopper, but water was available. All exposures were started at the same time of the day, between 10.30-11 a.m. Apart from the 3-h fast, normal chow was available concurrently with chocolate throughout the studies in order to provide nutrition also to the rats that avoided eating the novel food, as its avoidance was generally monitored for as long as it persisted, even up to several days. At the time of exposure, the rats weighed 238 $\pm 31 \mathrm{~g}$ (mean $\pm \mathrm{SD}, \mathrm{n}=90$ ). Within each experiment, rats were randomly distributed into groups, which were matched for body weight. At the end of the study, carbon dioxide was used for euthanasia and rats subjected to tissue sampling.

In Exp. 1A, AHR agonists FICZ (0.1 mg/kg), BNF (60 mg/kg), BaP $(150 \mathrm{mg} / \mathrm{kg}$ ) or their vehicle (sunflower oil with $2.5 \% \mathrm{DMSO}$ ) for the control group were administered once $(4 \mathrm{ml} / \mathrm{kg}$, ig), each on their own ( $\mathrm{n}=6$ for all groups). Right after the treatment, as the novel food item, $30 \mathrm{~g}$ of milk chocolate (Panda milk chocolate, Vaajakoski, Finland) was placed in each cage in addition to the regular feed. Chocolate consumption was measured by weighing the remaining piece at pre-designed intervals $(5,7,23,29,47,71,96,121$ and $144 \mathrm{~h}$ after exposure), and the intakes in the experimental groups were compared with that in the control group. The groups were monitored for as long as chocolate avoidance persisted, after which the rats were euthanized. For all groups, the liver was removed, trimmed and weighed, and then quickly frozen in liquid nitrogen. The samples were stored at $-80^{\circ} \mathrm{C}$ before being further processed.

In Exp. 1B, three doses of the selective AHR modulator C2 were tested $(4,20$ and $100 \mathrm{mg} / \mathrm{kg}, \mathrm{n}=6$ in all groups). Because the doses of 4 and $20 \mathrm{mg} / \mathrm{kg} \mathrm{C2}$ were originally intended for another study, their dosing protocol slightly deviated from the general scheme. For the $4 \mathrm{mg} / \mathrm{kg}$ group, $\mathrm{C} 2$ was administered first (4 $\mathrm{ml} / \mathrm{kg}$, ig), followed by a dose of vehicle (sunflower oil with 6\% DMSO; $0.7 \mathrm{ml}$, ig) $4 \mathrm{~h}$ later. For the $20 \mathrm{mg} / \mathrm{kg}$ group, the same vehicle was administered first ( $2 \mathrm{ml} / \mathrm{kg}$, ip), followed $2 \mathrm{~h}$ later by C2 (5 ml/kg, ig). For the $100 \mathrm{mg} / \mathrm{kg}$ group, a single dose of C2 (5 ml/kg, ig) was administered, as well as an equal amount of its vehicle for the control group (PEG-400, used for all C2 solutions). In all of these groups, milk chocolate was offered immediately after treatment with $\mathrm{C} 2$, as for the other AHR agonist groups in the previous study. Despite the divergences in exposures within this experiment, we deemed it important to present also these data since the behavioural outcomes did not differ from that caused by $100 \mathrm{mg} / \mathrm{kg} \mathrm{C2}$. Chocolate consumption was measured at 5, 7, 9 and $24 \mathrm{~h}$ for all C2 groups. In addition, it was done at 30 and 46 or $48 \mathrm{~h}$ for the $20 \mathrm{mg} / \mathrm{kg}$ and $100 \mathrm{mg} / \mathrm{kg}$ groups, and further at 55 and $70 \mathrm{~h}$ for the $100 \mathrm{mg} / \mathrm{kg}$ group. After euthanasia, the liver, duodenum and stomach were sampled for all groups, frozen quickly in liquid nitrogen and stored at $-80^{\circ} \mathrm{C}$ before being further processed. 
In Exps. 1A \& 1B, chocolate intake was measured at 5 and $7 \mathrm{~h}$. However, because these studies revealed that only the controls often just started consuming chocolate around these time points, a single measurement at $6 \mathrm{~h}$, which provided essentially the same information, was used in subsequent studies. To render the data comparable, we calculated the mean of 5- and 7-h intakes to represent 6-h chocolate consumption in Exps. 1A \& 1B.

A follow-up study (Exp. 2) was performed to test the specificity of the novel food avoidance to AHR activation (assessed by induction of xenobiotic-metabolizing enzymes of the AHR battery) as opposed to an activation of other nuclear receptors (assessed here by induction of the CAR-regulated xenobiotic-metabolizing gene for CYP2B1). The study was performed identically to Exp. 1A, but instead of AHR agonists, the animals were exposed (ig) to the CAR agonist TPD (10 mg/kg; $\mathrm{n}=12)$, and compared with a control group that received a dose of vehicle (sunflower oil with 6\% DMSO; $n=6$ ). These groups were monitored for $24 \mathrm{~h}$ and chocolate consumption was measured at 6 and $24 \mathrm{~h}$ after exposure before euthanasia. From 7 rats of the TPD group and all control rats, the liver was removed, trimmed and weighed. In addition, specimens of duodenum and stomach were taken. All samples were quickly frozen in liquid nitrogen and stored at $-80^{\circ} \mathrm{C}$ before being further processed.

Exp. 3 was designed to find out the persistence of the novel food avoidance, and to elucidate the role of the AHR in maintaining the avoidance response. Immediately after administration (ig) of a single dose of either FICZ (0.1 mg/kg), BNF (60 mg/kg) or vehicle (sunflower oil with 2.5\% DMSO; $\mathrm{n}=6$ for all groups), the rats were presented with milk chocolate for $6 \mathrm{~h}$, placed at the bottom of the cages as before so that they could get acquainted with it. Chocolate was then weighed and removed, and the rats were returned to shared cages with their pairs (of the same dosage group) and housed routinely for two weeks. After this period, during which the test substances were expected to be eliminated, the rats were moved again into their original individual cages. The following day, 14 days after the AHR-agonist exposure, the pieces of chocolate collected previously were returned to the cages. Chocolate consumption was again measured at pre-designed intervals ( $6 \mathrm{~h}$ directly after exposure, and 2, 6, 24, 48, 72 and $96 \mathrm{~h}$ after re-introduction of chocolate two weeks later) and the groups followed for as long as chocolate avoidance persisted. The amount of chocolate eaten in the experimental groups was again compared with that in the control group. 


\subsection{RNA isolation and RT-qPCR}

Total RNA was extracted from the liver for all control and study groups (except Exp. 3), and for selected groups also from the duodenum, stomach, caecum and colon. For the isolation, Sigma GenElute ${ }^{\mathrm{TM}}$ Mammalian Total RNA Miniprep Kit was used according to the manufacturer's protocol (Sigma-Aldrich, St. Louis, MO, USA). RNA was then treated with Ambion ${ }^{\circledR}$ TURBO DNA-free ${ }^{\mathrm{TM}}$ DNase treatment and removal reagent (Life Technologies, Carlsbad, CA, USA). The concentration of total RNA was measured by a Nanodrop UV Spectrophotometer (Thermo Fisher Scientific, Waltham, MA, USA) and RNA purity verified by 260/280 and $260 / 230 \mathrm{~nm}$ ratios. Total RNA was reverse transcribed to CDNA at $50^{\circ} \mathrm{C}$ for $1 \mathrm{~h}$ using M-MLV RT RNase $\mathrm{H}$ Point Mutant (Promega, Fitchburg, WI, USA). For each reaction $(25 \mu \mathrm{l}), 100 \mathrm{U}$ of the enzyme and $800 \mathrm{ng}$ of RNA was used. Real-time quantitative PCR (HOT FIREPol ${ }^{\circledR}$ EvaGreen ${ }^{\circledR}$ qPCR Mix Plus (no ROX), Solis Biodyne, Tartu, Estonia) was performed on the RotorGene 3000 instrument (Qiagen, Hilden, Germany) to determine the mRNA levels of the xenobiotic-metabolizing enzyme genes Cyp1a1 and $C y p 2 b 1$ by absolute quantification using total RNA amount ( $20 \mathrm{ng} /$ reaction) for normalization (see Supplementary Table 1 for primer sequences) (Bustin 2002, Tichopad, et al. 2009). For selected groups, also the mRNA levels of the AHR battery genes Ahrr, Tiparp, Cyp1a2 and Ugt1 were determined. If the RT-qPCR result was below the detection limit, a conservative approach was taken and the sample given the value of the limit.

\subsection{Data analysis and statistics}

Statistical analysis of mRNA abundance data was carried out by Student's t-test for independent samples or one-way ANOVA and Student-Newman-Keuls post-hoc test using the SPSS Statistics software (IBM Corp. Released 2013. IBM SPSS Statistics for Windows, Version 22.0. Armonk, NY, USA). In case of nonhomogeneous variances in ANOVA (as assessed by Levene's test), values were log-transformed and then reanalysed by one-way ANOVA, in addition to using Kruskal-Wallis non-parametric ANOVA, followed by the Dunn-Bonferroni post-hoc multiple comparison test. Chocolate intakes over time were statistically analysed using mixed between/within subject ANOVAs. For this purpose, the data were verified for normal distribution by Shapiro-Wilk's test, equality of error variances and covariance matrices was assessed by Levene's and Box's tests, respectively, and the homogeneity of the variances of the differences between all combinations of levels of the within-subjects factor (sphericity) by Mauchly's test. Significant main effects were further analysed by pairwise comparisons using Dunn's (1964) procedure with a Bonferroni correction for multiple comparisons and Kruskal-Wallis $\mathrm{H}$ test followed by multiple comparisons. The level of significance was set at $p<0.05$ in all other cases except for Box's test where only values $p<0.001$ were considered significant. 


\section{Results}

\subsection{Ability of AHR agonists to cause avoidance of an unfamiliar food item in rats}

In Exp. 1A, the aim was to study whether AHR agonists FICZ, BNF and BaP, which most likely have shorter elimination half-lives and a lower potency than TCDD, are also able to cause avoidance of a novel food. As hypothesized, all of them induced practically total abstinence from consumption of novel chocolate (Fig. 1A). However, its duration varied: 1 day for FICZ, 2-3 days for BNF and 3-4 days for BaP. Based on behavioural observation, the limit for fading of the avoidance was set at $\sim 3 \mathrm{~g}$ of daily chocolate consumption, as $3 \mathrm{~g}$ was about half of the amount the controls consumed in the first $24 \mathrm{~h}$ after exposure $(5.6 \pm 2.0 \mathrm{~g})$, and also roughly the amount after which consumption started increasing quite rapidly.

For a statistical comparison of chocolate consumption over time for rats treated with the established AHR agonists in Exp. 1A, chocolate eating rates (g/h) were calculated for 5 periods up to $48 \mathrm{~h}$ (Fig. 1B), and these were collectively analysed by a mixed between/within subject ANOVA. The covariance matrices proved to be non-homogeneous (Box's test, $p<0.001$ ). Therefore, the interaction term (treatment $x$ time) could not be assessed. However, there was a statistically significant difference among treatments, $F(3,20)=20.927$, $p<0.001$, partial $\eta^{2}=0.758$. Subsequently, a Kruskal-Wallis $H$ test followed by multiple comparisons were separately run for all time periods to determine which of the treatment groups differed from one another at the $p<0.05$ level. During the first time period $(0-5 \mathrm{~h})$, no significant differences existed. Between $5-7 \mathrm{~h}, \mathrm{BaP}$ differed from control. Between 7-23 h, BaP differed from both control and FICZ, and BNF from control. BaP continued to differ from control and FICZ also during the last two periods, 23-29 and 29-47 $\mathrm{h}$ after exposure. Considered together with the 24 -h chocolate intakes (Fig. 1A), the result confirms that in addition to TCDD, also shorter-acting AHR agonists induce avoidance of unfamiliar food items in rats. 

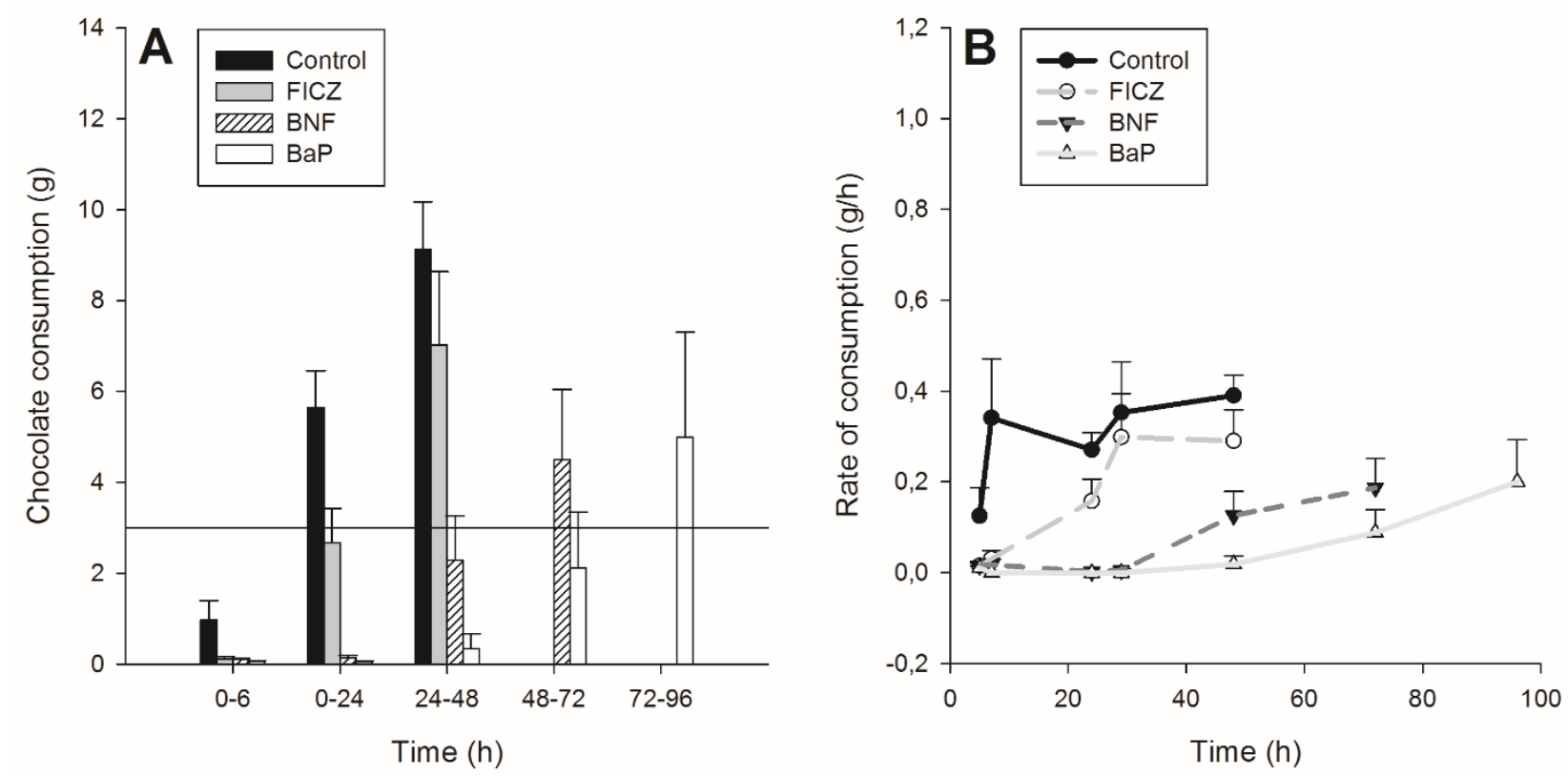

Fig. 1. Consumption of chocolate in Exp. 1A within 6- or 24-h periods (panel $A$, mean +SE) and chocolate consumption rate $(\mathrm{g} / \mathrm{h}$ ) between time points of measurement (panel $B$; mean $+\mathrm{SE}$ ). The rats were treated with a single ig dose of either the vehicle; FICZ $(n=6), \operatorname{BNF}(n=6)$ or $B a P(n=6)$. The reference line in A marks consumption of $\mathbf{3}$, which was considered the limit value for the end of the avoidance phase. Each group was monitored for chocolate consumption only for as long as the avoidance persisted, and thus there are no measurement results beyond these time points.

In Exp. 1B, we also tested three doses (100, 20 and $4 \mathrm{mg} / \mathrm{kg}$; in this order) of the selective AHR modulator C2. Similarly to the result with the other AHR activators, also C2 induced a total and comparable avoidance of the novel food at all tested dose levels, persisting for $2-3$ days at $100 \mathrm{mg} / \mathrm{kg}$ (Fig. 2). The 20 and $4 \mathrm{mg} / \mathrm{kg}$ dose groups were only monitored for up to 48 and $24 \mathrm{~h}$, respectively, and then euthanized and sampled before the avoidance had passed to make sure that activation of AHR could be verified. 

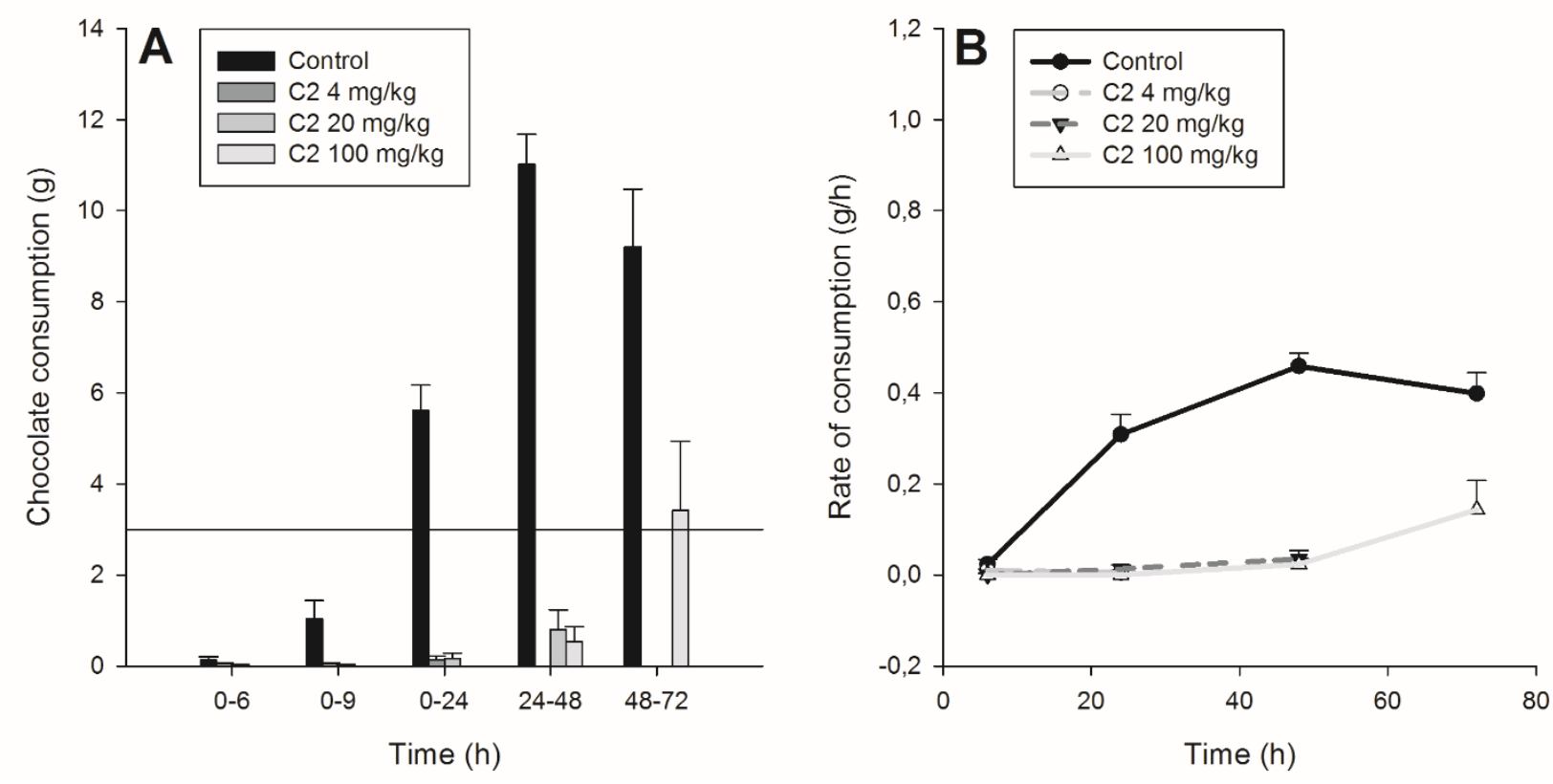

Fig. 2. Consumption of chocolate in Exp. 1B within 6-, 9- or 24-h periods (panel A; mean +SE) and chocolate consumption rate $(\mathrm{g} / \mathrm{h}$ ) between time points of measurement (panel $B$; mean $+S E$ ). The rats were treated with a single ig dose of one of the three doses of $C 2$ ( $n=6$ at each dose), plus vehicle in 4 and $20 \mathrm{mg} / \mathrm{kg}$ groups, or just vehicle in the control group ( $n=6)$. Other conditions are as in Fig. 1 . The time chocolate consumption was monitored varied between groups: $24 \mathrm{~h}$ for $4 \mathrm{mg} / \mathrm{kg}$, $48 \mathrm{~h}$ for $20 \mathrm{mg} / \mathrm{kg}$ and $72 \mathrm{~h}$ for $100 \mathrm{mg} / \mathrm{kg}$, thus there are no results for those groups beyond these time points.

In all three C2 dose groups in Exp. 1B, there was a clear and statistically significant induction of hepatic Cyp1a1 induction (130, 100 and 1700-fold, respectively, for the 100, 20 and $4 \mathrm{mg} / \mathrm{kg}$ groups; liver was sampled approximately at 74, 50 and $26 \mathrm{~h}$ after exposure). However, none of the experimental groups in Exp. $1 \mathrm{~A}$ differed from the control group in a statistically significant fashion in hepatic CYP1A1 mRNA abundance (Supplementary Table 2). This lack of difference is likely due to late tissue sampling, because each group was monitored for longer than avoidance persisted ( $50 \mathrm{~h}$ for FICZ, $74 \mathrm{~h}$ for BNF and $148 \mathrm{~h}$ for BaP). Even though tissue sampling times were different (Supplementary Table 2), a statistical comparison of the AHR agonist groups with the controls was deemed justified, because the Cyp1a1 expression level in the control group can be expected to remain practically constant irrespective of time after exposure to vehicle. Previously, identical or lower single doses of the established AHR agonists have been shown to be capable of inducing CYP1A1 in liver in vivo: for FICZ in mice, within 1-3 h after percutaneous application on the back of the ear (10 $\mathrm{ng}$ ) (Wincent, et al. 2012) or after an ip injection (1, 10 and $100 \mu \mathrm{g} / \mathrm{kg}$ ) (Mukai and Tischkau 2007); and for BNF and $\mathrm{BaP}$ in rats, within $24 \mathrm{~h}$ after gastric gavage (60 and $150 \mathrm{mg} / \mathrm{kg}$, respectively) (Hodek, et al. 2013). However, fading of the chocolate avoidance did not consistently coincide with subsidence of the hepatic 
enzyme induction in a few individual rats (Supplementary Table 2). While a few rats still exhibited elevated expression levels of Cyp1a1 expression even though they were already eating chocolate, some others had not started to consume chocolate although their Cyp1a1 expression levels did not differ from those of controls.

\subsection{Linkage between novel food avoidance and AHR activation}

The aim of Exp. 2 was to elucidate whether the avoidance effect is specific to activation of the AHR or whether it can be elicited by nuclear receptor activation in general. In this study, the CAR agonist TPD was used to cause a strong phenobarbital-type induction of CYP2B drug-metabolizing enzymes (Pustylnyak, et al. 2009). In contrast to the results obtained with the AHR agonists in Exp. 1, TPD did not influence chocolate consumption at all (Fig. 3), with the exception of one outlier rat that was excluded for reasons discussed further below. By $24 \mathrm{~h}$ after exposure, the other TPD-exposed rats consumed $6.8 \mathrm{~g}( \pm 2.2 \mathrm{~g}$ ) of chocolate, whereas in the control group the corresponding consumption was $6.2 \mathrm{~g}( \pm 3.0 \mathrm{~g})$.
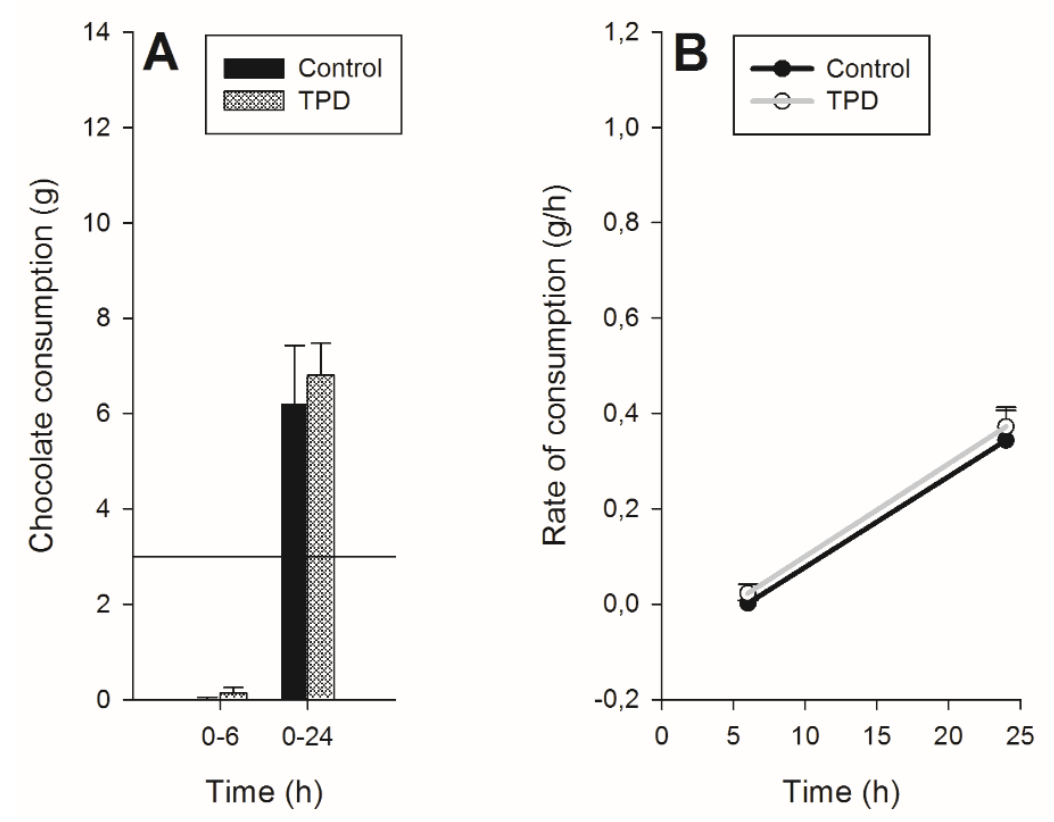

Fig. 3. Consumption of chocolate in Exp. 2 within 6- or 24-h periods (panel A; mean +SE) and chocolate consumption rate $(\mathrm{g} / \mathrm{h})$ between measured time points (panel $\mathrm{B}$; mean $+\mathrm{SE}$ ). The rats were treated with a single ig dose of either the vehicle $(n=6)$ or TPD $(n=11)$. Other conditions are as in Fig. 1. 
Although the CAR agonist TPD failed to elicit chocolate avoidance, it caused a sustained and notable induction of Cyp2b1 expression (about 1000-fold) in the liver (Table 1). Furthermore, TPD did not induce the hepatic genes of the AHR battery examined except for a tiny (3.3-fold) enhancement of Cyp1a1 expression. In duodenum, TPD only increased Cyp2b1 expression (by 25-fold). In stomach, there was no statistically significant induction of Cyp2b1 or any other gene by TPD. The changes in the AHR gene battery induced by TPD and AHR agonists C2 and TCDD are summarised in Table 1, which illustrates that the avoidance behaviour (Fig. 2) correlates specifically with AHR activation, but not with TPD-induced CAR activation (Fig. 3).

To verify that the avoidance behaviour is mediated by the AHR, we attempted to reverse it with two AHRantagonists: CH-223191 (Zhao, et al. 2010) and GNF351 (Smith, et al. 2011). However, administered separately ig as a single dose ( $13 \mathrm{mg} / \mathrm{kg}$ of $\mathrm{CH}-223191$ and $5 \mathrm{mg} / \mathrm{kg}$ of GNF-351), both antagonists failed to modify Cyp1a1 gene induction caused by a single dose of FICZ $(0.1 \mathrm{mg} / \mathrm{kg}$ ig). Thus, it was no surprise that they also failed to alleviate the avoidance behaviour. Similarly, a single dose of $\mathrm{CH}-223191$ failed to modify both enzyme induction and avoidance by $\mathrm{C} 2(15 \mathrm{mg} / \mathrm{kg}$ ig or $10 \mathrm{mg} / \mathrm{kg}$ ip of antagonist together with 4 or 20 $\mathrm{mg} / \mathrm{kg}$ ig of agonist, respectively). These outcomes were presumably at least partly due to insufficient doses and/or pharmacokinetic reasons, as in vitro, $\mathrm{CH}-223191$ is able to antagonise Cyp1a1 induction by $\mathrm{C} 2$ (Mahiout et al., manuscript in preparation).

As already mentioned, there was one outlier rat in the TPD group. This rat did not consume practically any chocolate $(0.3 \mathrm{~g})$ during the $24 \mathrm{~h}$ of monitoring, exhibiting avoidance comparable to that in the BNF and BaP groups. RT-qPCR analysis revealed that this individual's Cyp1a1 and Cyp2b1 expression profiles differed drastically from those of the other 6 rats in the TPD group (Table 1). More specifically, while Cyp2b1 induction in the liver and duodenum was similar to that in the rest of the TPD group, Cyp1a1 was induced 300-fold in the stomach of this rat alone. To put this magnitude into perspective, it is about half of that caused by 4 $\mathrm{mg} / \mathrm{kg}$ of the novel AHR modulator C2. This dose of $\mathrm{C} 2$, in turn, increased hepatic Cyp1a1 expression approximately 5 times as much as did $100 \mu \mathrm{g} / \mathrm{kg}$ TCDD at $24 \mathrm{~h}$ post-exposure (Table 1 ). 
Table 1. Differences between TPD- and AHR agonist-induced changes in the expression of selected indicative AHR core battery genes in the liver, duodenum and stomach. The fold changes ${ }^{1}$ induced by TPD $(10 \mathrm{mg} / \mathrm{kg})$ in S-D rats are compared with those induced by TCDD ${ }^{2}$ in Long-Evans rats, or C2 (4 $\mathrm{mg} / \mathrm{kg}$ ) in S-D rats (all vs. 5-6 controls). The results from the outlier rat in TPD group are also included (vs. 6 controls). The tissue sampling time is indicated as $h$ after exposure. Those fold changes that differed significantly $(p<0.05)$ from controls are in bold. For the outlier rat, fold changes have not been analysed statistically.

\begin{tabular}{|c|c|c|c|c|c|c|c|c|c|c|}
\hline \multirow[t]{2}{*}{ Gene } & \multicolumn{4}{|l|}{ Liver } & \multicolumn{3}{|c|}{ Duodenum } & \multicolumn{3}{|c|}{ Stomach } \\
\hline & $\begin{array}{l}\text { TPD } \\
(n=6)\end{array}$ & $\begin{array}{l}\text { Outlier in } \\
\text { TPD group }\end{array}$ & $\begin{array}{l}\text { TCDD } \\
(n=5)\end{array}$ & $\begin{array}{l}\text { C2 } \\
(n=6)\end{array}$ & $\begin{array}{l}\text { TPD } \\
(n=6)\end{array}$ & $\begin{array}{l}\text { Outlier in } \\
\text { TPD group }\end{array}$ & $\begin{array}{l}\text { C2 } \\
(n=6)\end{array}$ & $\begin{array}{l}\text { TPD } \\
(n=6)\end{array}$ & $\begin{array}{l}\text { Outlier in } \\
\text { TPD group }\end{array}$ & $\begin{array}{l}\text { C2 } \\
(n=6)\end{array}$ \\
\hline Time (h) & 28 & 28 & 24 & 28 & 28 & 28 & 28 & 28 & 28 & 28 \\
\hline Cyp1a1 & 3.3 & 2.7 & 350 & 1700 & ns & 10 & 90 & ns & 300 & 700 \\
\hline Cyp1a2 & ns & 0.6 & 15 & 10 & nd & nd & nd & nd & nd & nd \\
\hline Cyp2b1 & 1000 & 900 & 0.4 & ns & 25 & 70 & ns & ns & 15 & ns \\
\hline Tiparp & ns & 0.4 & 15 & ns & ns & 1.1 & ns & ns & 2.5 & ns \\
\hline Ugt1 & ns & 0.5 & 5.9 & ns & ns & 0.9 & ns & ns & 2.2 & 2.4 \\
\hline
\end{tabular}

${ }^{1}$ Fold change $=$ the ratio between the mean values for exposed and control rats

${ }^{2}$ The data for the TCDD group is from a previous study (Lindén, et al. 2014), where TCDD-sensitive Long-Evans (Turku/AB) rats were exposed to a single ig dose of $100 \mu \mathrm{g} / \mathrm{kg}$ TCDD. The cDNA for these samples had been reverse-transcribed previously, but qPCR was performed with the same primers and in the same conditions as in this study.

Ns = non-significant

$\mathrm{Nd}=$ not determined 


\subsection{Mode of action of the AHR-agonist-induced novel food avoidance in rats}

Exp. 3 was conducted to find out the persistence of the novel food avoidance and to elucidate the role of the AHR in maintaining the avoidance response. The study groups were first exposed to an AHR activator, either FICZ or BNF, while the control group was administered the vehicle. The novel chocolate was then presented on two occasions: first for a mere $6 \mathrm{~h}$, and again after a two-week interval, when it was left in the cages. Similarly to previous experiments, many of the exposed rats nibbled only minute amounts of chocolate during the $6 \mathrm{~h}$ at the first phase (Fig. 4A), and in fact none of the BNF-treated animals ate measurable amounts of it. Of the FICZ-treated rats, only two tasted the chocolate at this phase. At the re-introduction two weeks after the exposure, both AHR activators still provoked avoidance of it, which resembled that of the first encounter in Exp. 1A. While controls reached the set limit value of $3 \mathrm{~g}$ chocolate intake by approximately 6 h, for rats treated with FICZ or BNF this took 6-24 h or 24-48 h, respectively (Fig. 4A).

Chocolate intake rate (g/h) after re-introduction (Fig. 4B) was also assessed by mixed ANOVA over four time periods. The interaction term treatment $x$ time was not significant, whereas the treatment main effect was: $F(2,15)=4.798, p=0.024$, partial $\eta^{2}=0.390$. Subsequent pairwise comparisons and Kruskal-Wallis $H$ tests further found that BNF exhibited a statistically significant $(p<0.05)$ difference from control during the first period ( $0-2 \mathrm{~h}$ ). These results imply that once chocolate feeding fully commences at the re-introduction phase, it increases in a similar fashion in controls and AHR agonist-treated rats, but its onset is delayed by AHR agonists. The outcome is also visible in Fig. $4 \mathrm{~B}$ as almost parallel curves from the second time point on. 

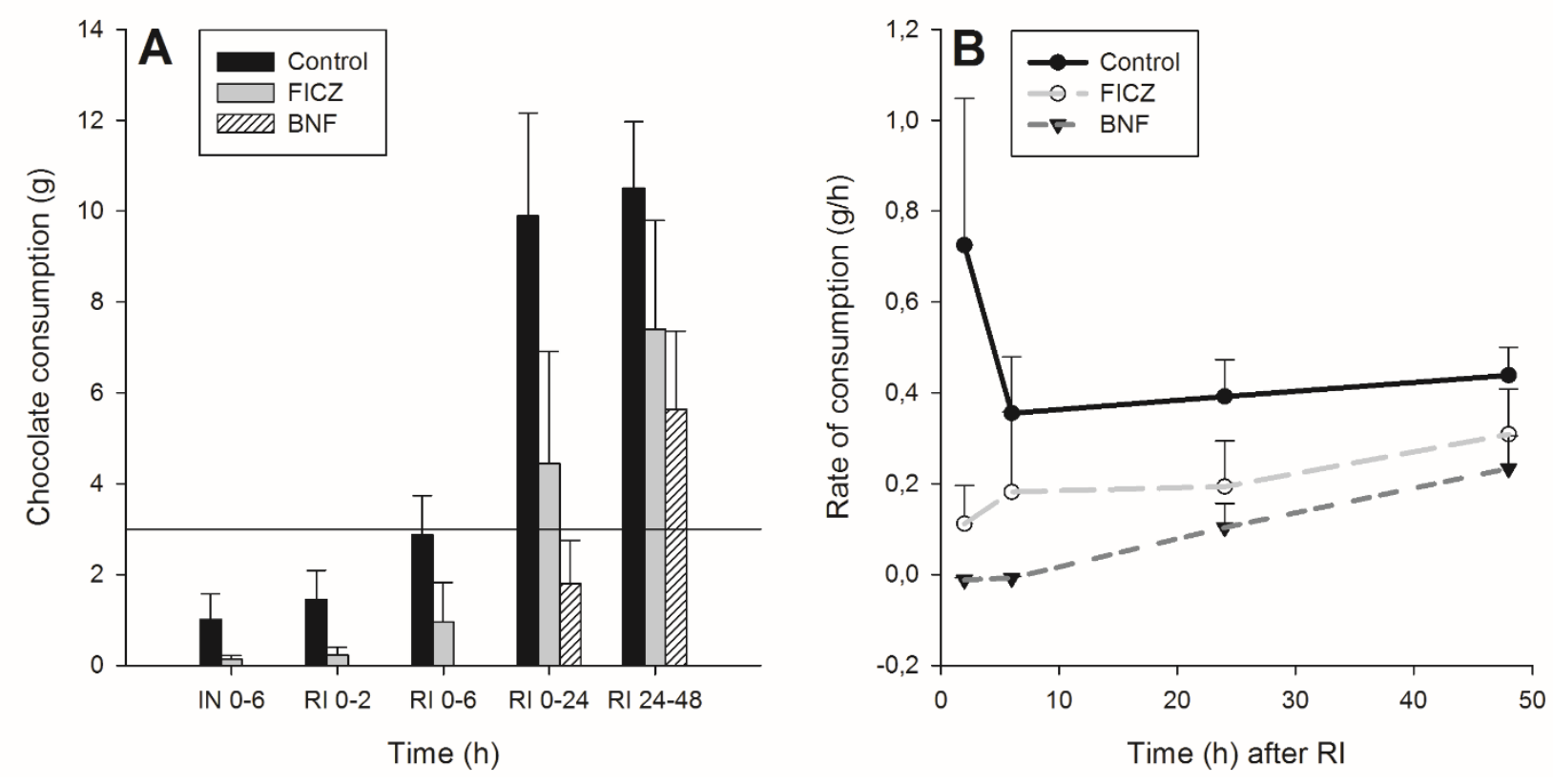

Fig. 4. Consumption of chocolate in Exp. 3 within the initial 6-h and re-introduction 2-, 6- or 24-h periods (panel $A$; mean $+S E$ ), and chocolate consumption rate $(g / h)$ between measured time points (panel $B$; mean $+S E)$. The rats were treated with a single ig dose of either the vehicle $(n=6)$, FICZ $(n=6)$ or BNF $(n=6)$ (Exp. 3). RI=Re-introduction of chocolate. At RI, the measurement was begun from 0 . Other conditions are as in Fig. 1. 


\section{Discussion}

It was previously discovered that when exposed to the environmental contaminant TCDD, rats and mice exhibit strong dislike towards novel food items presented to them concurrently with, or soon after the exposure (Lensu, et al. 2011a, Lensu, et al. 2011b). Virtually all biological effects of TCDD require the AHR to become manifest, and the fact that this avoidance was not seen in AHR knockout mice suggested a critical participation of AHR signalling in its mediation. However, the interpretation of this finding in mice was somewhat hampered by the surprising result that consumption of the novel food was even higher in TCDDtreated than in vehicle-treated AHR knockout mice (Lensu, et al. 2011b). Therefore, the present study set out to further investigate the involvement of the AHR in the avoidance behaviour towards novel food using rats, in which this response to TCDD was found to be more pronounced than in mice (Lensu, et al. 2011b). Moreover, we attempted to elucidate the roles of CTA and enhanced neophobia in this effect.

\section{Avoidance of novel food items by AHR agonists}

We established that in addition to TCDD, also the AHR agonists FICZ, BNF and BaP, as well as the novel selective AHR modulator C2 induce avoidance of a novel food item (chocolate). All the compounds tested in the present study most likely have considerably shorter elimination half-lives and, for the greater part, also lower AHR binding affinities than TCDD (the affinity of FICZ may be comparable to that of TCDD) (Okey, et al. 1984, Rannug, et al. 1987, Rannug, et al. 1995, Roy, et al. 1988). The duration of the rejection was, as expected, much shorter than with TCDD, and varied depending on the compound: approximately 1 day for FICZ, 2-3 days for BNF and C2, and 3-4 days for BaP. It is likely that the duration reflects the elimination halflives of these compounds, but the available literature data did not allow its precise verification. However, FICZ is known to be metabolized very rapidly in mammals, whereas BaP or its metabolites may linger on for several days in certain tissues (Ramesh, et al. 2001, Wincent, et al. 2012). As to BNF, kinetic data are missing, but indirect evidence from the present and previous studies (Masaki, et al. 1984, Zhang, et al. 1997), based on subsiding of microsomal enzyme induction, suggests that it is also eliminated effectively. There are no kinetic studies available yet on C2. Also, this result is well in line with the earlier finding that TCDD, which has a biological half-life of approximately 3 weeks in rats (Geyer, et al. 2002, Piper, et al. 1973, Pohjanvirta, et al. 1990), induced avoidance that persisted much longer: for 14 days with constant ad libitum access to chocolate, and up to several weeks after that, when rats had 24-h intermittent accesses to chocolate once a week (Lensu, et al. 2011a). 
In addition to half-lives, there may have been other factors that influenced the duration of chocolate avoidance, as well. For one, while the doses used were chosen based on previous literature data to provide reliable induction of drug-metabolizing enzymes in the liver (Hodek, et al. 2013, Mukai and Tischkau 2007, Wincent, et al. 2012), they were probably not comparable in potency with each other, which may have played a role in the differences in durations that were seen. In particular, the $150 \mathrm{mg} / \mathrm{kg}$ dose used for BaP is quite high, considering that $\mathrm{BaP}$ at $100 \mathrm{mg} / \mathrm{kg}$ orally has been reported to cause adverse effects in rats, including transient reduction of motor activity (Knuckles, et al. 2001, Saunders, et al. 2002). This side effect may well have contributed to the avoidance of the novel food in the case of BaP. It is noteworthy, though, that even the dose of $200 \mathrm{mg} / \mathrm{kg}$ was reported not to produce malaise in rats (Saunders, et al. 2002).

Although malaise is a subjective experience and thus poorly amenable to studying in laboratory animals, it is unlikely to be critically involved in the avoidance response caused by AHR agonists. In keeping with the report by Saunders et al. (2002) concerning BaP, no sign of gastrointestinal malaise was detected here in the general behaviour of the rats after exposure to any of the test compounds. It would also seem unlikely of the examined agents that those possessing AHR activation potential would all cause malaise because their structures varied widely. Moreover, a previous study, which tackled the role of nausea or gastrointestinal malaise in TCDD-elicited hypophagia, found that even at lethal doses there was little evidence in favour of an appreciable contribution by those conditions (Pohjanvirta, et al. 1994). Additionally, all the three doses (4$100 \mathrm{mg} / \mathrm{kg}$ ) used of $\mathrm{C} 2$ in the present study were far below those causing any overt toxicity of this compound (Mahiout et al., manuscript in preparation), and yet they resulted in a reliable, comparable and substantial chocolate avoidance.

Two further effects that could be related to the avoidance behaviour seen here are hypophagia and anxiety. Chow intake was not measured in this study in part due to technical reasons, but also because it has already been studied with TCDD in respect of hypophagia and the novel food avoidance behaviour (Lensu, et al. 2011a). Wasting syndrome is an extreme form of hypophagia that is a characteristic effect of acute toxicity of TCDD and other dioxins especially in rats, but it has not been seen with any other AHR-agonists (Neal, et al. 1979, Pohjanvirta and Tuomisto 1994). As even with TCDD, the doses that trigger the avoidance of novel foods fall far below those causing wasting syndrome or in fact any hypophagia, we consider it safe to assume that hypophagia is not likely to occur with the AHR agonists used here either. This view is reinforced by the fact that when in a recent study (Mahiout et al., manuscript in preparation) C2, or a closely related compound C4, were administered to Sprague-Dawley rats ig daily at the maximal levels technically achievable (100 $\mathrm{mg} / \mathrm{kg}$ and $75 \mathrm{mg} / \mathrm{kg}$ for $\mathrm{C} 2$ and $\mathrm{C} 4$, respectively) on 5 consecutive days (the rats were fed on regular chow), 
body weight gain showed only a subtle retardation as compared with the vehicle control group. Yet, a far lower dose of $\mathrm{C} 2,4 \mathrm{mg} / \mathrm{kg}$, as a single treatment, was here capable of eliciting total refusal of novel food (chocolate) intake for at least $24 \mathrm{~h}$ in the same strain of rats. Furthermore, there were no appreciable differences in body weight gain between groups in the novel food avoidance experiments. Thus, it seems clear that the avoidance of food has had to be selectively directed at the novel item presented to these rats and could not have been caused by their general hypophagia.

As for anxiety, there are established tests in which an increased latency to consume familiar foods in a novel environment (hyponeophagia) is indicative of heightened anxiety (Dulawa 2009, Samuels and Hen 2011). Therefore, it is conceivable that anxiety might play a role also in the avoidance behaviour seen here. However, the results of a previous behavioural study with TCDD in adult H/W rats speak against anxiety. These rats are resistant to the acute lethality of TCDD but equal to other strains in their sensitivity to most biochemical and behavioural responses to TCDD measured, including Cyp1a1 induction. The study found no indication of heightened anxiety after TCDD treatment, even at very high doses, which for most rat strains would have proven lethal (Sirkka, et al. 1992). Thus, it seems unlikely that the far less toxic AHR agonists used in the current study would induce anxiety if there is no such effect with TCDD.

\section{Relationship of the avoidance behaviour with induction of drug-metabolizing enzymes}

In contrast to the outcome with all AHR agonists, the CAR agonist TPD did not elicit chocolate avoidance. However, it caused a sustained and notable induction of Cyp2b1 expression (about 1000-and 25-fold) in the liver and duodenum, respectively, while it did not induce the genes of the AHR battery tested, except for a tiny (3.3-fold) enhancement of Cyp1a1 expression in the liver. The former findings establish that the absence of novel food avoidance in the TPD group was not due to TPD having been ineffective or rapidly eliminated in rats. Also, these findings demonstrate that the CAR-activator TPD acts indeed essentially in a separate manner from the AHR, supporting the hypothesis that the avoidance effect is specifically connected to activation of the AHR, and not to that of any nuclear receptor and subsequent metabolic enzyme induction in general.

Previous studies with TCDD had revealed a conspicuous convergence of $E D_{50}$ values for induction of hepatic CYP1A1 and the novel-food avoidance. Since AHR signalling is by far the predominant positive regulator of Cyp1a1 gene expression (Ma 2001), the finding suggested a possibility of a causal relationship between AHR 
activation in the liver and the behavioural change (Lensu, et al. 2011b). In theory, the induction of drugmetabolizing enzymes might not only be an index of AHR activation but also functionally involved in the instigation of the novel food rejection, e.g. by generating a critical mediator metabolite. In the present study, however, the subsidence of chocolate avoidance did not always seem to correlate faithfully with hepatic Cyp1a1 gene induction levels in individual rats, although this result may have been affected by the late tissue sampling time point. By then the avoidance had already completely faded in many rats, which prevents inference of the temporal relationships between induction and novel-food avoidance. There were also two individual rats that still exhibited elevated expression levels of Cyp1a1 expression, even though they were already eating chocolate. However, it could be that they had bypassed their peak induction phase, with the recovery allowing chocolate intake. Finally, in the previous study enzyme activities were measured whereas we determined mRNA abundances, and these may not parallel (Pascal, et al. 2008). While our present findings are not necessarily incompatible with the hypothesis that the avoidance effect would be linked to AHR-mediated induction of drug-metabolizing enzymes, it seems that fading of the avoidance may not strictly coincide with that of hepatic enzyme induction. Hence, more studies are needed to clarify whether induction of xenobiotic metabolism plays a role in novel food avoidance, or whether there is merely correlation due to activation of the AHR, without causality.

In the CAR-agonist TPD-group, there was an interesting outlier rat that might give a hint about the underlying molecular mechanisms behind the avoidance behaviour. This rat did not consume practically any chocolate $(0.3 \mathrm{~g})$, unlike all other 11 rats that had received TPD. When its tissues were analysed by RT-qPCR, we discovered that while the Cyp2b1 expression profile in the liver and duodenum was similar to the rest of the TPD group examined (900- and 70-fold increases compared with the controls, respectively), there was also a clear (300-fold) elevation in Cyp1a1 expression in the stomach, but not in the liver, while in the TPD group there was no appreciable induction of Cyp1a1 in either (Table 1). The Cyp1a1 induction levels in the stomach of the outlier resemble the hepatic Cyp1a1 induction seen in TCDD-exposed rats (data from stomach not available) and stomach Cyp1a1 induction instigated by the novel selective AHR modulator C2 (Table 1). Although factors like Wnt/B-catenin signalling (Vaas, et al. 2014) and Sp1 transcription factor (Kobayashi, et al. 1996) have been shown to be capable of somewhat enhancing Cyp1a1 expression, such sizable induction probably necessitates AHR activation. Hence, the profile of Cyp1a1 and Cyp2b1 expressions in the abdominal tissues suggests that while this rat received TPD equally to the rest of the group, it was somehow also orally exposed to a readily degradable AHR agonist. Zhao et al. (2013) have previously shown that AHR agonists are abundant in our environment, so this rat might have been exceptionally active in chewing its bedding material, plastic hiding tube etc. While $\mathrm{n}$ is only one here, this individual rat reinforces the view that the novel-food avoidance is an exquisitely sensitive response to AHR agonists. Furthermore, the fact that Cyp1a1 
was not notably induced in the liver while there was a substantial increase in its expression in the stomach, points to a key role for the upper GI tract in the kindling of the avoidance response by AHR activation. This would also be in keeping with the previous finding that TCDD was more effective in eliciting this response when administered by gavage as compared with ip injection, although at least part of the difference in effectiveness may have been due to differences in absorption rates (Lensu, et al. 2011a). However, further studies are necessary to verify these inferences.

\section{Role of enhanced neophobia and CTA in the avoidance response}

We further showed that when rats initially had only $6 \mathrm{~h}$ of access to chocolate upon exposure to the AHR activators FICZ or BNF, the avoidance response was still clearly present two weeks later when chocolate was offered again. It appears safe to assume that this time point was after the compounds had been eliminated, as we were unable to detect any statistically significant Cyp1a1 induction already at 50-148 $\mathrm{h}$ post-exposure with equal doses of FICZ and BNF in Exp. 1A. That could suggest that AHR activation is essential in triggering the avoidance but might no longer be required during its maintenance. This hypothesis is supported by the finding in Exp. $1 \mathrm{~A}$ that some individual rats continued to exhibit chocolate avoidance although their hepatic enzyme induction had levelled off. On the other hand, at the second encounter chocolate avoidance did subside at a faster rate than at the first one, especially in the BNF group. Thus, at this point the results about the role of the AHR in maintaining the avoidance of novel foods are inconclusive.

The findings of the present study are also inconclusive as to the primary behavioural phenomenon underlying the AHR-agonist-induced avoidance of novel foods. It is conceivable that AHR agonists could enhance neophobia to such an extent that it would remain effective up to the re-encounter with chocolate. This possibility is reinforced by the fact that with constant presence of chocolate in the cages, the avoidance waned within a couple of days. The duration of CTA should be considerably longer, although it is usually measured by providing the conditioned stimulus available only intermittently in contrast to its constant presence here, which could influence the rate of avoidance extinction. Moreover, connecting particularly the taste of a novel food with subsequent malaise has been traditionally considered a critical prerequisite for the development of CTA according to its definition as a taste aversion [for example (Lin, et al. 2014)], whereas in all of our experiments many of the rats in the AHR agonist groups avoided the chocolate without even tasting it. This may then signify that the avoidance behaviour could not be due to CTA. However, also other than taste stimuli are known to induce conditioned aversions, and odours have been shown to be capable of inducing CTA (or more precisely designated as conditioned odour aversion) [for example (Bertrand, et al. 
2009, Chapuis, et al. 2009, Lin, et al. 2014, Slotnick, et al. 1997, Tovar-Díaz, et al. 2011)]. Further, common novel flavours employed in CTA studies such as glucose, sucrose or saccharine (offered dissolved in water from bottles) might not have a strong enough odour to be perceived even by rats, making tasting them indispensable in the development of CTA. In the case of chocolate, however, due to its strong and rich smell, it is conceivable that no gustatory signals are required to induce CTA, permitting even odour alone to cause the avoidance behaviour seen here. The close and entwined relationships of taste and smell senses would also support this assumption, but it should be directly tested in the future.

Previous studies with TCDD seem to provide support for both enhanced neophobia and induced CTA. The finding that chocolate avoidance in rats could be elicited even if chocolate was first presented as long as one day after TCDD exposure (Lensu, et al. 2011a) strongly argues in favour of enhanced neophobia. In contrast, a number of other facts attest to the supremacy of CTA. Firstly, clear avoidance also emerges, albeit not quite as strikingly, when rats have been accustomed to chocolate for a few days or up to a month prior to TCDD exposure (Lensu, et al. 2011a, Tuomisto, et al. 2000). Secondly, Tuomisto et al. (2000) showed that rats that had been given chocolate within $12 \mathrm{~h}$ of TCDD exposure, consumed on day 13 post-exposure cheese (which at that point was a novel food item for them) equally compared with the control group. However, these same rats still demonstrated chocolate avoidance on day 19 post-exposure. It should be noted that TCDD also induces avoidance of cheese, when it is offered as a novel food shortly after TCDD exposure (Tuomisto, et al. 2000). And finally, a parallel finding was done by Lensu et al. (2011a): 7 days after exposure to TCDD coupled with an unfamiliar food (chocolate or powdered chow) that had subsequently been available for 1 day, the rats preferred a completely novel food (powdered chow or chocolate) to the one they had been offered as unfamiliar on the day of exposure. This suggests that neophobia is not intensified by TCDD. Overall, the AHR agonist-triggered avoidance of novel foods thus seems to contain elements of both CTA and enhanced neophobia. Further studies are needed to dissect their contributions in different conditions.

\section{Future endeavours}

The present study raises several important questions for future research to elucidate. First, it will be intriguing to find out whether there is a relationship between the intestinal malaise-induced CTA and novel food avoidance triggered by AHR activation. Most of the known inducers of CTA, including the "gold standard" substance LiCl, have not been reported to exhibit affinity to the AHR. However, very few of them have been examined for this property, and it is also possible that they affect AHR indirectly. For example, LiCl is a known GSK3b-inhibitor and thus a Wnt signalling activator, and Wnt signalling in turn can modify AHR 
activity (Grimes and Jope 2001, Klein and Melton 1996, Schneider, et al. 2014). Examining LiCl in the recently introduced AHR knockout rat model (Harrill, et al. 2013) would thus be of great interest. Second, the critical site(s) of AHR activity for the avoidance response and the mechanism by which the signal is then delivered to the central nervous system call for scrutiny. Studies in vagotomised rats could be illuminating in this respect. Third, the possible implications of our findings for humans remain to be established. CTA is a common clinical problem in human medicine with chemo- and radiotherapy, but also possible in other nausea inducing conditions, such as food poisoning and motion sickness, and has even been utilized in alcoholism treatment as "emetic therapy" (Arwas, et al. 1989, Bernstein 1985, Elkins 1991, Scalera 2002). Finally, recent studies have established unexpected important regulatory functions for AHR signalling in GI tract innate immunology and microbial control (Kiss, et al. 2011, Moura-Alves, et al. 2014). Their possible interrelationships or coexistence with the avoidance response warrant targeted studies, which may broaden our view of the physiological significance of AHR signalling. 


\section{Conclusions}

Avoidance of novel foodstuffs is a behavioural change in rats triggered not only by TCDD but also by other AHR agonists, and the behaviour seems to be specifically linked to induction of AHR activity. It is also shared by both endogenous and exogenous AHR activators. However, the duration of the avoidance response appears to depend on the agonist. In the absence of the novel food after initial encounter, the avoidance response may be retained far longer than the agonist itself. In addition, our findings point to the stomach as a possible key target for AHR agonists to elicit avoidance of unfamiliar food items. 


\section{Acknowledgements}

The work was financially supported by Academy of Finland (Grant no. 261232). We wish to thank Dr. Vladimir O. Pustylnyak (Institute of Molecular Biology and Biophysics SB RAMS, Novosibirsk, Russia) for kindly providing TPD for our studies. Equally, Dr. Lars Pettersson (Immunahr AB, Lund, Sweden) is thanked for kindly providing C2. In addition, the authors wish to acknowledge Susanna Lukkarinen for her valuable technical contribution in processing samples and performing RT-qPCR. Laboratory science student Anssi Vuorensola is thanked for his participation in processing of samples. Dr. Hannu Rita and Dr. Jani Anttila are acknowledged for providing advice on statistics and data presentation. The staff at Laboratory Animal Centre (LAC) of the University of Helsinki is thanked for their help with practicalities and cooperation; especially Leena Liesirova, Sanna Karumaa and Lea Karvonen for providing help whenever needed.

Preliminary results of some of the data were presented in the following meetings: Society of Toxicology's $54^{\text {th }}$ Annual Meeting, 22-26 March 2015, San Diego, California (SOT 2015) and the $51^{\text {st }}$ Congress of the European Societies of Toxicology (Eurotox 2015), 13-16 September 2015, Porto, Portugal. 
References

Abraham, K., Krowke, R., Neubert, D., 1988. Pharmacokinetics and biological activity of 2,3,7,8tetrachlorodibenzo-p-dioxin - 1. Dose-dependent tissue distribution and induction of hepatic ethoxyresorufin O-deethylase in rats following a single injection. Arch. Toxicol. 62, 359-368.

Arwas, S., Rolnick, A., Lubow, R.E., 1989. Conditioned taste aversion in humans using motion-induced sickness as the US. Behav. Res. Ther. 27, 295-301.

Bergander, L., Wahlström, N., Alsberg, T., Bergman, J., Rannug, A., Rannug, U., 2003. Characterization of in vitro metabolites of the aryl hydrocarbon receptor ligand 6-formylindolo[3,2-b]carbazole by liquid chromatography-mass spectrometry and NMR. Drug Metab. Dispos. 31, 233-241.

Bergander, L., Wincent, E., Rannug, A., Foroozesh, M., Alworth, W., Rannug, U., 2004. Metabolic fate of the Ah receptor ligand 6-formylindolo[3,2-b]carbazole. Chem. Biol. Interact. 149, 151-164.

Bermudez-Rattoni, F., 2014. The forgotten insular cortex: Its role on recognition memory formation. Neurobiol. Learn. Mem. 109, 207-216.

Bernstein, I.L., 1985. Learned food aversions in the progression of cancer and its treatment. Ann. New York Acad. Sci. Vol. 443, 365-380.

Bertrand, D., Yannick, S., Mathilde, B., Frédéric, L., Nadine, R., Guillaume, F., 2009. Critical role of insular cortex in taste but not odour aversion memory. Eur. J. Neurosci. 29, 1654-1662.

Bock, K.W., Köhle, C., 2006. Ah receptor: Dioxin-mediated toxic responses as hints to deregulated physiologic functions. Biochem. Pharmacol. 72, 393-404.

Bustin, S.A., 2002. Quantification of mRNA using real-time reverse transcription PCR (RT-PCR): Trends and problems. J. Mol. Endocrinol. 29, 23-39.

Chapuis, J., Garcia, S., Messaoudi, B., Thevenet, M., Ferreira, G., Gervais, R., Ravel, N., 2009. The way an odor is experienced during aversive conditioning determines the extent of the network recruited during retrieval: A multisite electrophysiological study in rats. J. Neurosci. 29, 10287-10298.

Denison, M.S., Soshilov, A.A., He, G., Degroot, D.E., Zhao, B., 2011. Exactly the same but different: Promiscuity and diversity in the molecular mechanisms of action of the aryl hydrocarbon (dioxin) receptor. Toxicol. Sci. 124, 1-22.

Dulawa, S.C., 2009. Novelty-Induced Hypophagia, in: Gould, D.T. (Ed.), Mood and Anxiety Related Phenotypes in Mice: Characterization using Behavioral Tests. Humana Press, Totowa, NJ, pp. 247-259.

Dunn, O.J., 1964. Multiple Comparisons Using Rank Sums. Technometrics 6, 241-252.

Elkins, R.L., 1991. An appraisal of chemical aversion (emetic therapy) approaches to alcoholism treatment. Behav. Res. Ther. 29, 387-413.

Esser, C., Rannug, A., Stockinger, B., 2009. The aryl hydrocarbon receptor in immunity. Trends Immunol. 30, 447-454. 
Fujii-Kuriyama, Y., Kawajiri, K., 2010. Molecular mechanisms of the physiological functions of the aryl hydrocarbon (dioxin) receptor, a multifunctional regulator that senses and responds to environmental stimuli. Proc. Jpn. Acad. Ser. B Phys. Biol. Sci. 86, 40-53.

Geyer, H.J., Schramm, K., Anton Feicht, E., Behechti, A., Steinberg, C., Brüggemann, R., Poiger, H., Henkelmann, B., Kettrup, A., 2002. Half-lives of tetra-, penta-, hexa-, hepta-, and octachlorodibenzo-pdioxin in rats, monkeys, and humans-a critical review. Chemosphere 48, 631-644.

Grant, V.L., 1987. Do conditioned taste aversions result from activation of emetic mechanisms? Psychopharmacology 93, 405-415.

Grimes, C.A., Jope, R.S., 2001. The multifaceted roles of glycogen synthase kinase $3 \beta$ in cellular signaling. Prog. Neurobiol. 65, 391-426.

Guzmán-Ramos, K., Bermúdez-Rattoni, F., 2011. Post-learning molecular reactivation underlies taste memory consolidation. Front. Syst. Neurosci.

Hahn, M.E., Karchner, S.I., 2011. Structural and Functional Diversification of AHRs during Metazoan Evolution, in: Pohjanvirta, R. (Ed.), The AH Receptor in Biology and Toxicology. John Wiley \& Sons, Inc., Hoboken, NJ, USA, pp. 387-403.

Harrill, J.A., Hukkanen, R.R., Lawson, M., Martin, G., Gilger, B., Soldatow, V., LeCluyse, E.L., Budinsky, R.A., Rowlands, J.C., Thomas, R.S., 2013. Knockout of the aryl hydrocarbon receptor results in distinct hepatic and renal phenotypes in rats and mice. Toxicol. Appl. Pharmacol. 272, 503-518.

Hodek, P., Koblihová, J., Kizek, R., Frei, E., Arlt, V.M., Stiborová, M., 2013. The relationship between DNA adduct formation by benzo[a]pyrene and expression of its activation enzyme cytochrome P450 1A1 in rat. Environ. Toxicol. Pharmacol. 36, 989-996.

Kaisarevic, S., Dakic, V., Hrubik, J., Glisic, B., Lübcke-von Varel, U., Pogrmic-Majkic, K., Fa, S., Teodorovic, I., Brack, W., Kovacevic, R., 2015. Differential expression of CYP1A1 and CYP1A2 genes in H4IIE rat hepatoma cells exposed to TCDD and PAHs. Environ. Toxicol. Pharmacol. 39, 358-368.

Kiss, E.A., Vonarbourg, C., Kopfmann, S., Hobeika, E., Finke, D., Esser, C., Diefenbach, A., 2011. Natural aryl hydrocarbon receptor ligands control organogenesis of intestinal lymphoid follicles. Science 334, 15611565.

Kiviranta, H., Vartiainen, T., Tuomisto, J., 2002. Polychlorinated dibenzo-p-dioxins, dibenzofurans, and biphenyls in fishermen in Finland. Environ. Health Perspect. 110, 355-361.

Klein, P.S., Melton, D.A., 1996. A molecular mechanism for the effect of lithium on development. Proc. Natl. Acad. Sci. U. S. A. 93, 8455-8459.

Knuckles, M.E., Inyang, F., Ramesh, A., 2001. Acute and subchronic oral toxicities of benzo[a]pyrene in F344 rats. Toxicol. Sci. 61, 382-388.

Kobayashi, A., Sogawa, K., Fujii-Kuriyama, Y., 1996. Cooperative interaction between AhR·Arnt and Sp1 for the drug-inducible expression of CYP1A1 gene. J. Biol. Chem. 271, 12310-12316.

Lee, J.S., Cella, M., McDonald, K.G., Garlanda, C., Kennedy, G.D., Nukaya, M., Mantovani, A., Kopan, R., Bradfield, C.A., Newberry, R.D., Colonna, M., 2012. AHR drives the development of gut ILC22 cells and 
postnatal lymphoid tissues via pathways dependent on and independent of Notch. Nat. Immunol. 13, 144152.

Lensu, S., Tuomisto, J.T., Tuomisto, J., Pohjanvirta, R., 2011a. Characterization of the 2,3,7,8tetrachlorodibenzo-p-dioxin (TCDD)-provoked strong and rapid aversion to unfamiliar foodstuffs in rats. Toxicology 283, 140-150.

Lensu, S., Tuomisto, J.T., Tuomisto, J., Viluksela, M., Niittynen, M., Pohjanvirta, R., 2011b. Immediate and highly sensitive aversion response to a novel food item linked to AH receptor stimulation. Toxicol. Lett. 203, 252-257.

Lin, J., Arthurs, J., Reilly, S., 2016. Conditioned taste aversions: From poisons to pain to drugs of abuse. Psychon Bull Rev, 1-17.

Lin, J., Arthurs, J., Reilly, S., 2014. Conditioned taste aversion, drugs of abuse and palatability. Neurosci. Biobehav. Rev. 45, 28-45.

Lindén, J., Lensu, S., Pohjanvirta, R., 2014. Effect of 2,3,7,8-Tetrachlorodibenzo-p-dioxin (TCDD) on hormones of energy balance in a TCDD-sensitive and a TCDD-resistant rat strain. Int. J. Mol. Sci. 15, 1393813966.

Ma, Q., 2001. Induction of CYP1A1. The AhR/DRE paradigm: transcription, receptor regulation, and expanding biological roles. Curr. Drug Metab. 2, 149-164.

Ma, Q., 2011. Overview of AHR Functional Domains and the Classical AHR Signaling Pathway: Induction of Drug Metabolizing Enzymes, in: Pohjanvirta, R. (Ed.), The AH Receptor in Biology and Toxicology. John Wiley \& Sons, Inc., Hoboken, NJ, USA, pp. 33-45.

Masaki, R., Matsuura, S., Tashiro, Y., 1984. A biochemical and electron microscopic study of changes in the content of cytochrome P-450 in rat livers after cessation of treatment with phenobarbital, ß-naphtoflavone or 3- methylcholanthrene. Cell Struct. Funct. 9, 53-66.

McMillan, B.J., Bradfield, C.A., 2007. The aryl hydrocarbon receptor sans xenobiotics: Endogenous function in genetic model systems. Mol. Pharmacol. 72, 487-498.

Moura-Alves, P., Faé, K., Houthuys, E., Dorhoi, A., Kreuchwig, A., Furkert, J., Barison, N., Diehl, A., Munder, A., Constant, P., Skrahina, T., Guhlich-Bornhof, U., Klemm, M., Koehler, A.-., Bandermann, S., Goosmann, C., Mollenkopf, H.-., Hurwitz, R., Brinkmann, V., Fillatreau, S., Daffe, M., Tümmler, B., Kolbe, M., Oschkinat, H., Krause, G., Kaufmann, S.H.E., 2014. AhR sensing of bacterial pigments regulates antibacterial defence. Nature 512, 387-392.

Mukai, M., Tischkau, S.A., 2007. Effects of tryptophan photoproducts in the circadian timing system: Searching for a physiological role for aryl hydrocarbon receptor. Toxicol. Sci. 95, 172-181.

Neal, R.A., Beatty, P.W., Gasiewicz, T.A., 1979. Studies of the mechanisms of toxicity of 2,3,7,8tetrachlorodebenzo-p-dioxin (TCDD). Ann. N. Y. Acad. Sci. 320, 204-213.

Núñez-Jaramillo, L., Ramírez-Lugo, L., Herrera-Morales, W., Miranda, M.I., 2010. Taste memory formation: Latest advances and challenges. Behav. Brain Res. 207, 232-248. 
Okey, A.B., Dubé, A.W., Velia, L.M., 1984. Binding of Benzo(a)pyrene and Dibenz(a,h)anthracene to the Ah Receptor in Mouse and Rat Hepatic Cytosols. Cancer Res. 44, 1426-1432.

Pascal, L.E., True, L.D., Campbell, D.S., Deutsch, E.W., Risk, M., Coleman, I.M., Eichner, L.J., Nelson, P.S., Liu, A.Y., 2008. Correlation of mRNA and protein levels: Cell type-specific gene expression of cluster designation antigens in the prostate. BMC Genomics 9.

Piper, W.N., Rose, J.Q., Gehring, P.J., 1973. Excretion and tissue distribution of 2,3,7,8 tetrachlorodibenzo $p$ dioxin in the rat. Environ. Health Perspect. No. 5, 241-244.

Pohjanvirta, R., Tuomisto, J., 1994. Short-term toxicity of 2,3,7,8-tetrachlorodibenzo-p-dioxin in laboratory animals: Effects, mechanisms, and animal models. Pharmacol. Rev. 46, 483-549.

Pohjanvirta, R., Unkila, M., Tuomisto, J., 1994. TCDD-induced hypophagia is not explained by nausea. Pharmacol. Biochem. Behav. 47, 273-282.

Pohjanvirta, R., Unkila, M., Tuomisto, J., 1993. Comparative acute lethality of 2,3,7,8-tetrachlorodibenzo-pdioxin (TCDD), 1,2,3,7,8-pentachlorodibenzo-p-dioxin and 1,2,3,4,7,8-hexachlorodibenzo-p-dioxin in the most TCDD-susceptible and the most TCDD-resistant rat strain. Pharmacol. Toxicol. 73, 52-56.

Pohjanvirta, R., Vartiainen, T., Uusi-Rauva, A., Monkkonen, J., Tuomisto, J., 1990. Tissue distribution, Metabolism, and excretion of 14c-tcdd in a tcdd-susceptible and a tcdd-resistant rat straina. Pharmacol. Toxicol. 66, 93-100.

Pustylnyak, V., Pivovarova, E., Slynko, N., Gulyaeva, L., Lyakhovich, V., 2009. Species-specific induction of CYP2B by 2,4,6-tryphenyldioxane-1,3 (TPD). Life Sci. 85, 815-821.

Ramesh, A., Inyang, F., Hood, D.B., Archibong, A.E., Knuckles, M.E., Nyanda, A.M., 2001. Metabolism, bioavailability, and toxicokinetics of Benzo(a)pyrene in F-344 rats following oral administration. Exp. Toxicol. Pathol. 53, 275-290.

Rannug, A., Rannug, U., Rosenkranz, H.S., Winqvist, L., Westerholm, R., Agurell, E., Grafström, A.K., 1987. Certain photooxidized derivatives of tryptophan bind with very high affinity to the Ah receptor and are likely to be endogenous signal substances. J. Biol. Chem. 262, 15422-15427.

Rannug, U., Rannug, A., Sjöberg, U., Li, H., Westerholm, R., Bergman, J., 1995. Structure elucidation of two tryptophan-derived, high affinity Ah receptor ligands. Chem. Biol. 2, 841-845.

Roy, M., Fernandez, N., Lesca, P., 1988. Binding characteristics of 4-S proteins from rat and mouse liver. High affinity of ellipticines. Eur. J. Biochem. 172, 593-599.

Samuels, B.A., Hen, R., 2011. Novelty-Suppressed Feeding in the Mouse, in: Gould, D.T. (Ed.), Mood and Anxiety Related Phenotypes in Mice: Characterization using Behavioral Tests, Volume II. Humana Press, Totowa, NJ, pp. 107-121.

Saunders, C.R., Ramesh, A., Shockley, D.C., 2002. Modulation of neurotoxic behavior in F-344 rats by temporal disposition of benzo(a)pyrene. Toxicol. Lett. 129, 33-45.

Scalera, G., 2002. Effects of conditioned food aversions on nutritional behavior in humans. Nutr. Neurosci. 5, 159-188. 
Schneider, A.J., Branam, A.M., Peterson, R.E., 2014. Intersection of AHR and Wnt signaling in development, health, and disease. Int. J. Mol. Sci. 15, 17852-17885.

Shen, C., Chen, Y., Huang, S., Wang, Z., Yu, C., Qiao, M., Xu, Y., Setty, K., Zhang, J., Zhu, Y., Lin, Q., 2009. Dioxin-like compounds in agricultural soils near e-waste recycling sites from Taizhou area, China: Chemical and bioanalytical characterization. Environ. Int. 35, 50-55.

Sirkka, U., Pohjanvirta, R., Nieminen, S.A., Tuomisto, J., Ylitalo, P., 1992. Acute neurobehavioural effects of 2,3,7,8-tetrachlorodibenzo-p-dioxin (TCDD) in Han/Wistar rats. Pharmacol. Toxicol. 71, 284-288.

Slotnick, B.M., Westbrook, F., Darling, F.M.C., 1997. What the rat's nose tells the rat's mouth: Long delay aversion conditioning with aqueous odors and potentiation of taste by odors. Anim. Learn. Behav. 25, 357369.

Smith, K.J., Murray, I.A., Tanos, R., Tellew, J., Boitano, A.E., Bisson, W.H., Kolluri, S.K., Cooke, M.P., Perdew, G.H., 2011. Identification of a high-affinity ligand that exhibits complete aryl hydrocarbon receptor antagonism. J. Pharmacol. Exp. Ther. 338, 318-327.

Sugihara, K., Okayama, T., Kitamura, S., Yamashita, K., Yasuda, M., Miyairi, S., Minobe, Y., Ohta, S., 2008. Comparative study of aryl hydrocarbon receptor ligand activities of six chemicals in vitro and in vivo. Arch. Toxicol. 82, 5-11.

Tichopad, A., Kitchen, R., Riedmaier, I., Becker, C., Ståhlberg, A., Kubista, M., 2009. Design and optimization of reverse-transcription quantitative PCR experiments. Clin. Chem. 55, 1816-1823.

Tovar-Díaz, J., González-Sánchez, H., Roldán-Roldán, G., 2011. Association of stimuli at long intervals in conditioned odor aversion. Physiol. Behav. 103, 144-147.

Tuomisto, J.T., Viluksela, M., Pohjanvirta, R., Tuomisto, J., 2000. Changes in food intake and food selection in rats after 2,3,7,8- tetrachlorodibenzo-p-dioxin (TCDD) exposure. Pharmacol. Biochem. Behav. 65, 381387.

Tuomisto, J.T., Viluksela, M., Pohjanvirta, R., Tuomisto, J., 1999. The AH receptor and a novel gene determine acute toxic responses to TCDD: Segregation of the resistant alleles to different rat lines. Toxicol. Appl. Pharmacol. 155, 71-81.

Vaas, S., Kreft, L., Schwarz, M., Braeuning, A., 2014. Cooperation of structurally different aryl hydrocarbon receptor agonists and $B$-catenin in the regulation of CYP1A expression. Toxicology 325, 31-41.

Van Den Berg, M., Birnbaum, L., Bosveld, A.T.C., Brunström, B., Cook, P., Feeley, M., Giesy, J.P., Hanberg, A., Hasegawa, R., Kennedy, S.W., Kubiak, T., Larsen, J.C., Van Leeuwen, F.X.R., Liem, A.K.D., Nolt, C., Peterson, R.E., Poellinger, L., Safe, S., Schrenk, D., Tillitt, D., Tysklind, M., Younes, M., Wærn, F., Zacharewski, T., 1998. Toxic equivalency factors (TEFs) for PCBs, PCDDs, PCDFs for humans and wildlife. Environ. Health Perspect. $106,775-792$.

Verendeev, A., Riley, A.L., 2012. Conditioned taste aversion and drugs of abuse: History and interpretation. Neurosci. Biobehav. Rev. 36, 2193-2205.

Wei, Y., Helleberg, H., Rannug, U., Rannug, A., 1998. Rapid and transient induction of CYP1A1 gene expression in human cells by the tryptophan photoproduct 6-formylindolo[3,2-b]carbazole. Chem. Biol. Interact. 110, 39-55. 
Welzl, H., D'Adamo, P., Lipp, H., 2001. Conditioned taste aversion as a learning and memory paradigm. Behav. Brain Res. 125, 205-213.

White, S.S., Birnbaum, L.S., 2009. An overview of the effects of dioxins and dioxin-like compounds on vertebrates, as documented in human and ecological epidemiology. J. Environ. Sci. Health Part C Environ. Carcinog. Ecotoxicol. Rev. 27, 197-211.

Wincent, E., Amini, N., Luecke, S., Glatt, H., Bergman, J., Crescenzi, C., Rannug, A., Rannug, U., 2009. The suggested physiologic aryl hydrocarbon receptor activator and cytochrome P4501 substrate 6formylindolo[3,2-b]carbazole is present in humans. J. Biol. Chem. 284, 2690-2696.

Wincent, E., Bengtsson, J., Bardbori, A.M., Alsberg, T., Luecke, S., Rannug, U., Rannug, A., 2012. Inhibition of cytochrome P4501-dependent clearance of the endogenous agonist FICZ as a mechanism for activation of the aryl hydrocarbon receptor. Proc. Natl. Acad. Sci. U. S. A. 109, 4479-4484.

Zhang, Q., Wikoff, J., Dunbar, D., Fasco, M., Kaminsky, L., 1997. Regulation of cytochrome P4501A1 expression in rat small intestine. Drug Metab. Dispos. 25, 21-26.

Zhao, B., Bohonowych, J.E.S., Timme-Laragy, A., Jung, D., Affatato, A.A., Rice, R.H., Di Giulio, R.T., Denison, M.S., 2013. Common Commercial and Consumer Products Contain Activators of the Aryl Hydrocarbon (Dioxin) Receptor. PLoS ONE 8(2).

Zhao, B., DeGroot, D.E., Hayashi, A., He, G., Denison, M.S., 2010. Ch223191 is a ligand-selective antagonist of the Ah (dioxin) receptor. Toxicol. Sci. 117, 393-403. 